\title{
Memórias do Curso de Pós-graduação EM PSICOlOGIA DA PUC-Rio: COMEMORANDO SEUS 40 ANOS $^{1}$
}

\author{
Terezinha Féres-Carneiro*
}

\section{RESUMO}

Contando a história do Curso de Pós-graduação em Psicologia da PUC-Rio, este texto é apresentado em comemoração aos seus 40 anos. Em 1966, o Departamento de Psicologia implantou o primeiro Curso de Mestrado do país na área. O Doutorado foi iniciado em 1985. Com grande tradição na área da Psicologia Clínica no Rio de Janeiro e no Brasil, esta foi a ênfase que, ao longo do tempo, predominou no nosso Programa de Pós-graduação. São ressaltadas as reformulações, as experiências inovadoras e os procedimentos pioneiros que marcaram sua história e permitiram que ele acompanhasse os novos desenvolvimentos da produção de conhecimento na área e, ao mesmo tempo, exercesse o papel de liderança que sempre lhe coube no cenário da Pós-graduação em Psicologia no Brasil.

Palavras-chave: História, psicologia clínica, pós-graduação, mestrado, doutorado

\section{Abstract}

The history of the Graduate Program in Psychology at the PUC-Rio UNIVERSITY: CELEBRATING 40 YEARS OF EXISTENCE

The history of the Graduate Program in Psychology at the PUC-Rio University is presented for the celebration of its 40 years of existence. In 1966, the Department of Psychology implemented the first Graduate Program for the Masters Degree in Psychology of the country. The Doctorate Program was initiated in 1985. Great tradition has always been the emphasis of our Graduate Program in the area of Clinical Psychology not only in Rio de Janeiro but also throughout Brazil. In its history are highlighted the reformulations, innovative experiences and pioneer

\footnotetext{
* Professora Titular do Departamento de Psicologia da PUC-Rio.
} 
procedures which marked its path and allowed it to follow-up the new developments in the production of knowledge in the field and at the same time, exercised a permanent leadership role in the psychology Graduate scene.

Keywords: History, clinical psychology, graduate program, masters degree, doctorate

Recentemente, a história do nosso Programa de Pós-graduação foi por mim contada nos dois últimos Simpósios da ANPEPP, em 2004, em Aracruz, no Espírito Santo, e em 2006, em Florianóplolis, em Santa Catarina. Na primeira ocasiāo tratava-se de uma Mesa sobre a implantação da Pós-graduação em Psicologia no Brasil, e contei, então, a história do primeiro curso de Psicologia do país. Na segunda, numa Mesa sobre "Experiências inovadoras de formação na Pós-graduação", os organizadores do evento deram à minha fala o título "Resiliência na Pósgraduação: a história de um Programa de 40 anos”, esperando que eu narrasse sobretudo as dificuldades encontradas e superadas ao longo de 4 décadas de experiência de formação na Pós-graduação. Foi com muita honra e muita emoção que desempenhei as tarefas que me foram atribuídas naquelas ocasiōes. Mas é com honra maior ainda, com redobrada emoção e com um carinho muito especial que aceitei e agradeço o delicado convite da Diretora do Departamento de Psicologia, Profa. Maria Elizabeth Ribeiro, para, nesta Mesa de Abertura do "Encontro nacional Trauma e Memória", falar em comemoração aos 40 anos, completados em 2006, do nosso Programa de Pós-graduação.

Foi em março de 1966 que o Departamento de Psicologia da PUC-Rio implantou o primeiro Curso de Mestrado em Psicologia do país, sob a Coordenação do Pe. Antonius Benko. A primeira dissertação de mestrado na área da Psicologia no Brasil, intitulada "Homeostase psíquica e agradabilidade", foi defendida no dia 20 de dezembro de 1968, por Leonel Correa Pinto, sob a orientação do professor Carlos Paes de Barros. Este curto prazo da defesa da primeira dissertação (menos de três anos) foi, à época, uma exceção. Nos primeiros anos de funcionamento da pós-graduação em Psicologia, na PUC-Rio, assim como nos cursos mais tradicionais de Pós-graduação, implantados no início da década de 70, os prazos oficiais para a conclusão dos Cursos de Mestrado eram muito mais longos do que os atuais; isto porque, à época, a maior parte das instituiçôes, em seus regulamentos internos, ou não fixavam prazos ou estabeleciam prazos muito dilatados para as defesas das dissertações.

Em 1972, quando apenas seis Cursos de Mestrado em Psicologia estavam sendo oferecidos no país, o Curso da PUC-Rio foi o primeiro a ser credenciado pelo Conselho Federal de Educação. Todavia, o Curso de Doutorado só foi im- 
plantado em 1985. Poderíamos nos perguntar por que o primeiro Programa a implantar o Mestrado no país demorou quase vinte anos para implantar o Doutorado, quando não foi assim em outros Cursos iniciados nos anos seguintes. Por exemplo, os dois Programas da USP, de Psicologia Experimental e de Psicologia Escolar e Desenvolvimento Humano, que começaram o Mestrado em 1970, implantaram o Doutorado em 1974.

Todavia, é importante lembrar que, em 1976, os Departamentos de Psicologia e de Educação da PUC-Rio implantaram um Doutorado conjunto. Fazíamos parte desta primeira turma, além de cinco colegas da Educação, os colegas e amigos da Psicologia: Bernard Rangé, Cílio Ziviani, Maria Euchares Mota, Vera Lemgruber e eu. Depois de um semestre, todos nós, da Psicologia, com exceção da Maria Euchares, desistimos deste curso e fomos, posteriormente, cada um num momento (com exceção de Vera Lemgruber, que fez o Curso de Medicina/Psiquiatria), fazer o Doutorado em outras instituições no Brasil ou no exterior. O referido Curso não foi uma experiência bem-sucedida enquanto parceria entre a Educação e a Psicologia e ficou, posteriormente, definido apenas como um Doutorado em Educação.

Para compreender melhor o adiamento da implantação do nível de Doutorado no Programa de Pós-graduação em Psicologia da PUC-Rio, é importante podermos falar um pouco de outros momentos de altos e baixos na sua experiência de formação.

Desde a sua criação, em 1966, até o ano de 1978, o Mestrado, que já tinha sido em vários momentos considerado centro de excelência, era oferecido em duas áreas de concentração: Psicologia Aplicada à Clínica e Psicologia Experimental. Recomendava-se que a Dissertação fosse de natureza empírica, mas a partir de 1970, com a contratação de um competente grupo de teóricos da Psicologia e da Psicanálise, dentre eles a professora Circe Navarro Vital Brasil e o professor Luiz Alfredo Garcia Rosa, isto foi objeto de longos debates, e a área de Psicologia Experimental passou a ser denominada de Teórico-Experimental e muitas dissertações de natureza teórica passaram a ser defendidas.

Em 1978, alguns professores saíram do Programa e, apesar de o corpo docente estar constituído por pesquisadores altamente qualificados de diferentes áreas, o processo de recredenciamento do Mestrado, feito pelo MEC, considerou o corpo docente limitado, em número, para duas áreas de concentração e o parecer foi desfavorável. Como as áreas de especialização dos docentes eram diversas e não havia uma concentração em nenhuma delas, neste momento - em que eu me encontrava na Direção do Departamento e o professor Aroldo Rodrigues na Coordenação de Pós-graduação -, o Programa, para atender à exigência do MEC 
através da Comissão de recredenciamento, optou por um Mestrado em uma única área, que foi então denominada de Processos Motivacionais. A escolha desta área, excessivamente ampla, refletiu a constituição do corpo docente da época.

Tendo em vista que, já na sua origem, esta área apresentava problemas, decidimos proceder a uma reavaliação da mesma. Considerávamos que a delimitação de uma única área de concentração deveria refletir uma real articulação e não apenas se constituir numa solução artificial para atender a uma exigência do recredenciamento. Tornava-se necessária então uma delimitação de objetivos mais específicos e uma concentração de recursos humanos para a consecução de tais objetivos.

Precisávamos ser criativos e inovadores para recuperarmos a qualidade da nossa formação que ficou meio abalada neste período. O que fizemos? Ao longo dos anos de 1980 e 1981, uma Comissão Especial composta por professores do Programa discutiu as reformulaçôes necessárias e apresentou uma proposta, que foi aprovada pelo conjunto dos professores da Pós-graduação e pelas instâncias internas da PUC-Rio, com área de concentração em Psicologia Clínica, implantada no ano seguinte.

A definição da área de concentração em Psicologia Clínica fundamentou-se, sobretudo, em quatro importantes considerações: 1) o papel de liderança exercido pelo Departamento de Psicologia da PUC-Rio em relação à tradição da Clínica no Rio de Janeiro; 2) a demanda dos candidatos (um levantamento realizado a partir dos requerimentos dos candidatos ao Mestrado nos anos de 1979, 1980 e 1981 indicou que 90\% deles buscavam a área de Clínica; 3) a inexistência, à época, desta área de concentração em outros Mestrados do Grande Rio; e 4) a então constituição do corpo docente. Enquanto discutia a necessidade de reformulação, o Programa ampliou seu corpo docente e, à medida que alguns professores de diferentes áreas se desligaram do Programa, as novas contratações foram concentradas na área de Clínica.

Em 1982, quando o professor Bernard Rangé dirigia o Departamento de Psicologia e eu coordenava a Pós-graduação, a reformulação da área de concentração em Psicologia Clínica foi implantada com três linhas de pesquisa (Teoria e Prática Psicanalítica, Linguagem e Construção do Sujeito e Práticas Institucionais e Desenvolvimento Humano). Tal reformulação levou o Curso a recuperar sua excelência e a ser avaliado, em 1984, com conceito A pela CAPES. Nesta ocasião, ainda como Coordenadora, eu tinha a idéia fixa de implantar o Doutorado para tirarmos o atraso dos anos anteriores, meio conturbados. Fui a Brasília, algumas vezes, discutir na CAPES com Rosana Arcoverde, então responsável pela área de avaliação, o Projeto de implantação do Doutorado que foi aprovado, neste mesmo ano, e iniciado em março de 1985. 
Nos oito anos que se seguiram, o Programa de Psicologia Clínica da PUCRio manteve o conceito A na CAPES, todavia nas avaliações de 92/93 e 94/95 o conceito caiu novamente para $\mathrm{B}$, tendo em vista que os prazos para a conclusão dos Cursos, sobretudo do Doutorado, voltaram a ficar muito longos, tendo havido também uma queda na produção bibliográfica do corpo docente. No início do ano de 1996, recebi da então Diretora do Departamento, professora Maria Euchares Mota, e dos colegas do Programa insistentes solicitações para que assumisse, mais uma vez, o cargo de Coordenadora de Pós-Graduação e Pesquisa. Havia nestas solicitações dos colegas a esperança de que pudéssemos recuperar a tradição de excelência, perdida nas duas avaliações anteriores.

Aceitei o desafio, passando a discutir com os professores a grande importância da produção docente e da produção discente no processo de recuperação da excelência do Programa. Discutimos mais uma vez uma proposta de reformulação dos Cursos de Mestrado e Doutorado, visando, sobretudo, à redução dos prazos de defesa das dissertações e teses e à articulação das disciplinas às quatro linhas de pesquisa agora propostas: Teoria e Prática Psicanalítica; Linguagem e Construção da Subjetividade; Instituições, Práticas Sociais e Culturais; e Família e Casal: Estudos Psicossociais e Psicoterapia. Reduzimos o número de disciplinas obrigatórias, que ficaram sendo apenas as disciplinas metodológicas e instrumentais para o desenvolvimento das dissertaçóes e teses, e articulamos melhor as eletivas aos temas das pesquisas desenvolvidas pelos professores e alunos. Tais medidas tornaram a produção do Programa mais consistente e articulada.

O regulamento interno da universidade, à época, estabelecia o prazo de 3 anos para a conclusão do Mestrado, com dois possíveis pedidos de prorrogação, ou seja, o mestrando poderia fazer o Curso em 4 anos. O prazo do Doutorado até esta data era de 6 anos, com duas possíveis prorrogações, assim o doutorando podia fazer o Curso em 7 anos. Era preciso ser mais realista que o rei para reduzir tais prazos.

Uma das principais críticas recebidas, na ocasião, era a de que nossos prazos de conclusão do Mestrado e do Doutorado eram extremamente longos. Uma experiência que se mostrou muito bem-sucedida foi o contato pessoal que, como Coordenadora, fiz com cada mestrando e cada doutorando e com todos os orientadores, ressaltando a importância para o Programa de que as defesas fossem realizadas sem prorrogação (nos anos anteriores, a quase totalidade dos alunos havia lançado mão do recurso da prorrogação). Estes contatos foram suficientes para aumentar o número de defesas de dissertações e teses de 15, em 1995, para 36 em 1996. Portanto, comprometer professores e alunos, de forma mais explícita, com o Programa é uma experiência que costuma dar ótimos resultados. 
Outra iniciativa que tomamos, na ocasiāo, em relação aos prazos, foi argumentar, várias vezes, com a Coordenação Central de Pós-graduação e Pesquisa da PUC-Rio que era preciso mudar os prazos da Universidade em relação às defesas de dissertaçóes e teses. Tentamos mostrar que prazos tão dilatados eram um desserviço que a Universidade prestava aos Programas, na medida em que a política de Pós-graduação do país estabelecia prazos muito mais curtos para as defesas. O fato é que, menos de dois anos depois destas insistentes conversas, a PUCRio reduziu de três para dois anos o prazo de defesa das dissertações e de seis para quatro anos o das teses, havendo sempre a possibilidade de duas prorrogações de seis meses cada.

Era preciso, portanto, continuar evitando as prorrogações. Para que a medida fosse mais oficializada, introduzimos um procedimento que, posteriormente, foi adotado também pela Coordenação Central de Pós-graduação e Pesquisa, nos mesmos moldes do nosso Programa. No ato da concessão da bolsa, logo após a matrícula, instituímos um termo de compromisso que todos os alunos teriam que assinar se comprometendo a defender a dissertação em dois anos e a tese em quatro, caso contrário passariam a pagar as mensalidades.

Pudemos lançar mão deste recurso, que de uma certa maneira estabelecia prazos mais curtos do que os da universidade (que ainda permitia um ano de prorrogação), na medida em que todos os alunos eram, e continuam sendo, bolsistas. Apesar de a PUC-Rio ser uma instituição privada, temos o privilégio de nenhum aluno, dos Cursos de Mestrado e de Doutorado em Psicologia, pagar mensalidade. Aqueles que não possuem bolsa da CAPES, do CNPq ou da FAPERJ são contemplados com uma bolsa da Vice-Reitoria Acadêmica, com isenção total de pagamento. A única situação, portanto, em que o aluno paga mensalidades é quando não cumpre, respectivamente, os prazos de 24 e 48 meses para defesa da dissertação e da tese, o que só em casos muito excepcionais tem ocorrido nos últimos anos.

Uma outra inovação, que implantamos no Programa, está relacionada ao cumprimento da exigência da CAPES de que aluno bolsista curse a disciplina Estágio de Docência na Graduação. Estabelecemos que os alunos da Pós-graduação só podem ministrar $1 / 3$ da disciplina oferecida à Graduação sob a supervisão do professor da disciplina e com a concordância do orientador. Esta medida tem o objetivo de evitar que os alunos do Mestrado e do Doutorado corram o risco de substituir professores da Graduação, sem terem a devida orientação e supervisão, neste momento importante de aprendizagem para eles. Desta forma, não só os bolsistas da CAPES cursam a referida disciplina, mas a maioria dos bolsistas do $\mathrm{CNPq}$ e daqueles que têm bolsa de isenção da Vice-reitoria Acadêmica escolhe 
espontaneamente cursar Estágio de Docência na Graduação. Esta possibilidade de um grande número de mestrandos e doutorandos atuarem em atividades de ensino na Graduação traz, sem dúvida, um benefício precioso para a formação dos mesmos.

Com o trabalho conjunto de professores e alunos, reduzimos os prazos de defesa de dissertações e de teses e aumentamos a produção qualificada docente e discente, recuperando assim a avaliação 5 na CAPES no biênio 96/97.

Entretanto, no triênio seguinte (98/99/2000), o Programa aumentou o prazo médio de defesas, sobretudo das teses de Doutorado (tendo em vista que o novo regulamento passou a ter vigência apenas para os alunos que entraram a partir de 1999), e teve a produção docente reduzida; além disto, foi ressaltado pela CAPES que uma das linhas de pesquisa apresentava produção bibliográfica muito baixa.

Em 2001, a então Diretora do Departamento, professora Ana Maria Rudge, e os colegas da Pós-Graduação insistiram para que eu aceitasse a Coordenação, mais uma vez, com o objetivo de recuperar o papel de liderança que o Programa de Psicologia Clínica da PUC-Rio, por tantos anos, exerceu no cenário nacional da Pós-Graduação. E, pela terceira vez, aceitei o desafio.

Tivemos, nesse momento, mais uma posição inovadora na Universidade. Discutimos, nas reuniōes do corpo docente, a necessidade de implantarmos no Programa o procedimento de credenciamento para orientação na Pós-graduação não apenas para a entrada dos professores no Programa, mas também para a permanência deles no mesmo. Tal procedimento foi aprovado pelo conjunto dos professores, que elegeram uma Comissão de Credenciamento composta por quatro docentes (dois professores associados e dois professores titulares).

Como resultado deste trabalho, no final de 2001, os professores que não apresentaram a produção bibliográfica considerada necessária pela referida Comissão não foram credenciados para orientar na Pós-graduação, não tendo recebido, assim, alunos novos. Tal procedimento passou a vigorar no regulamento dos Programas de Pós-graduação da PUC-Rio. Fazer isso, certamente, foi uma experiência difícil e dolorosa, pois implicou a saída de alguns colegas da Pós-graduação, mas era a única alternativa para recuperarmos o Programa. Como conseqüência do credenciamento, uma linha de pesquisa foi desativada, passando apenas a concluir os projetos e orientações já em andamento.

Além do credenciamento interno, abrimos um concurso com duas vagas, no final de 2002, no qual foram aprovados dois jovens pesquisadores, competentes e muito produtivos: Marcus André Vieira e Carlos Augusto Peixoto. Em seguida passamos a contar também com mais duas jovens e competentes professoras: uma 
recém-doutora apoiada pela FAPERJ - Monah Winograd - e uma bolsista PRODOC/CAPES - Andréa Seixas Magalhães - que foram posteriormente contratadas pelo Departamento quando do término das referidas bolsas.

Mais uma vez, os esforços envidados pelo corpo docente e pelo corpo discente da Pós-graduação, no sentido sobretudo de incrementar a produção bibliográfica e de reduzir os prazos de defesa das dissertaçôes e das teses, foram coroados com o resultado da avaliação da CAPES, referente ao triênio 2001/2002/2003, na qual nosso Programa recuperou a avaliação 5.

No segundo semestre de 2004, um novo arranjo das linhas de pesquisa foi discutido e proposto, visando à entrada na Pós-graduação de professores com produção bibliográfica de qualidade que se encontravam atuando apenas na Graduação. Atualmente, o Programa está organizado em 4 linhas de pesquisa: Psicanálise: clínica e cultura; Linguagem e construção da subjetividade; Família e casal: estudos psicossociais e psicoterapia; e Clínica e neurociências. Seu corpo docente é composto por 15 professores e o corpo discente por 37 mestrandos e 41 doutorandos. Já foram defendidas 609 dissertações e 118 teses. Em agosto deste ano, foi realizada a avaliação da CAPES referente ao triênio 2004/2005/2006, cujo resultado ainda não foi divulgado, mas acreditamos que manteremos a nota 5 da avaliação anterior, com um movimento ascendente em busca da nota 6 .

Como vimos, foram necessárias muitas reformulações e muitas experiências inovadoras, além de muitos procedimentos pioneiros, para que o Programa de Pós-graduação em Psicologia Clínica da PUC-Rio pudesse cumprir, nestas 4 décadas, a tarefa de produzir conhecimento e formar pesquisadores em nível de mestrado e de doutorado de forma competente para continuar exercendo o papel de liderança que sempre lhe coube no cenário da Pós-graduação em Psicologia no Brasil.

Sinto-me orgulhosa de ter participado tão intensamente desta história. Foi com a alegria daqueles que exercem prazerosa e apaixonadamente o seu ofício que exerci a Coordenação do nosso Programa de Pós-graduação por três mandatos, totalizando 14 anos. E é como muita emoção que, em nome de todos nós, professores, alunos e funcionários, presto a ele esta homenagem, parabenizando todos aqueles que colaboraram na construção da sua história.

Além dos 40 anos da nossa Pós-graduação, estamos comemorando também a maioridade da nossa revista Psicologia Clínica - cujo primeiro número foi publicado em agosto de 1986, quando a professora Maria Helena Novaes se encontrava na Coordenação de Pós-graduação e Pesquisa do Departamento. Graças ao esforço e à competência da professora Ana Maria Rugde, Editora da nossa Revista, que trabalhou arduamente para que a mesma fosse indexada nas 
mais importantes bases de dados da área, Psicologia Clinica obteve nas duas últimas avaliações da Comissão da CAPES/ANPEPP, a classificação Nacional A no Qualis da Psicologia.

Para finalizar, gostaria de prestar uma homenagem especial aos nossos mestres, alguns dos quais já falecidos, que foram pioneiros na implantação da Pósgraduação em Psicologia no Brasil e que compartilharam conosco, em várias ocasiōes, suas inquietações e seus projetos para a Psicologia brasileira. Eles, que foram inovadores, que nos deixaram uma preciosa herança e que nos ensinaram também, amorosamente, que a herança pode ser transformada, levando-nos como discípulos a não ter medo de ousar e de inovar, legado que, também nós, devemos deixar aos nossos alunos na nossa função de formá-los para o ensino e a pesquisa.

Nosso carinho e nossa gratidão a Pe. Antonius Benko, a Carlos Paes e Barros, a Aroldo Rodrigues, a Ângela Biaggio, a Circe Navarro Vital Brasil, a Charles Esbérard, a Maria Helena Novaes, a Monique Augras e a todos os mestres com quem tanto aprendemos como ser resilientes e ter experiências inovadoras na pósgraduação.

\section{NoTAS}

1 Esta é uma versão ampliada do texto apresentado na Mesa de Abertura do "Encontro Nacional Trauma e Memória”, realizado no Departamento de Psicologia da PUC-Rio nos dias 14 e $15 / 06 / 07$.

Recebido em 30 de junho de 2007 Aceito para publicação em 20 de agosto de 2007 